\title{
Licenciamento ambiental de empreendimentos turísticos em destinos ecoturísticos litorâneos do Ceará: reflexões críticas
}

\section{Environmental licensing of tourist projects in coastal ecotourism destinations of Ceará (Brazil): critical reflections}

\author{
Thays Regina Rodrigues Pinho
}

\begin{abstract}
RESUMO
O licenciamento ambiental para a instalação de grandes empreendimentos turístico-imobiliários é uma exigência legal, devido à singularidade ambiental dos ecossistemas presentes na zona costeira. O estudo, em tela, objetiva refletir criticamente sobre a construção de um documento fundamental para obtenção da licença ambiental, o Relatório de Impacto Ambiental (RIMA), que compila as informações do Estudo de Impacto Ambiental (EIA), especificamente de 04 empreendimentos localizados em destinos considerados ecoturísticos no Estado do Ceará. Trata-se de um estudo exploratório e descritivo, em que os procedimentos metodológicos se concentraram no estudo e sistematização dos processos conceituais e documentais pertinentes ao objeto de estudo, com pesquisas bibliográfica e documental. Houve a aplicação de técnicas investigativas para análise dos documentos, como a análise de conteúdo. A análise baseou-se em dois aspectos: a construção interdisciplinar dos RIMAs e a valorização turística de destinos como justificativa para o processo de mercantilização das praias e especulação imobiliária. Os resultados apontam que os RIMAs não apresentam um caráter interdisciplinar e utilizam o turismo como atividade indutora do desenvolvimento local, favorecendo a mercantilização das praias e a especulação imobiliária.
\end{abstract}

PALAVRAS-CHAVE: Ecoturismo; Interdisciplinaridade; Licenciamento Ambiental; Empreendimentos Turístico-Imobiliários. 


\section{ABSTRACT}

The environmental license for the installation of big tourist projects is a legal requirement due to environmental uniqueness of the ecosystems present in the coastal zone. The study objective critically reflect on the construction of a basic document for obtaining the environmental permit, the Environmental Impact Report, which compiles information on the Environmental Impact Assessment, specifically 04 projects located in ecotourism destinations in the state of Ceará. This is an exploratory and descriptive study, in which the methodological procedures focused on study systematically the conceptual and document processes relevant to the object of study, with bibliographical and documentary research. There was the application of analytic techniques for analysis of documents, such as content analysis. The analysis was based on two aspects: the interdisciplinary construction of RIMAs and the tourism development targets to justify the commercialization process of the beaches and speculation. The results show that the RIMAs don't have interdisciplinary character and use tourism as inducing activity of local development, favoring the marketing of beaches and speculation.

KEYWORDS: : Ecotourism; Interdisciplinary; Environmental Licensing; Tourist Projects.

\section{Introdução}

Muito se versa na literatura acadêmica e científica acerca do ordenamento jurídico que engloba o processo licitatório para empreendimentos com potencial poluidor. Na maioria dos casos, o enfoque se dá nas questões jurídicas e econômicas associadas a grandes obras e intervenções em setores produtivos como o da mineração, o energético e da construção civil. Pouco se reflete criticamente quando se trata do licenciamento ambiental de empreendimentos turístico-imobiliários ${ }^{1} \mathrm{em}$ destinos ecoturísticos litorâneos e seus resultados efetivos. Busca-se analisar o tema sob uma perspectiva interdisciplinar, destacando os processos para a gestão dos impactos ambientais a partir da instalação de obras turísticas.

Devido à singularidade ambiental dos ecossistemas presentes na zona costeira para instalar-se, os grandes empreendimentos turístico-imobiliários necessitam do licenciamento ambiental que prevê dentre outras diretivas, a adoção de medidas mitigadoras e compensatórias por modificações que possam provocar ao meio.

Tais ações são apresentadas em documentos que vão respaldar a avaliação de impactos ambientais, a saber o Estudo de Impacto Ambiental (EIA) e seu respectivo Relatório de Impacto Ambiental (RIMA). Tomando por base estes instrumentos de gestão ambiental de empreendimentos turísticos, é feito um estudo avaliativo dos mesmos, analisando-os criticamente sob o enfoque da interdisciplinaridade e dos procedimentos adotados na sua construção.

Objetiva-se, portanto, avaliar, especificamente, os RIMAs, que nortearam o licenciamento ambiental de quatro empreendimentos turísticoimobiliários em destinos considerados ecoturísticos do litoral do Estado do Ceará, a saber, 01 empreendimento em Flecheiras, 01 na Praia de Guajiru, 
ambos no município de Trairi, 01 em Cascavel e 01 em Paracuru, sob a luz da interdisciplinaridade e perspectiva de mercantilização turística das praias. Foram definidos parâmetros de análise conforme os preceitos da interdisciplinaridade. Além disso, fez-se uma análise de conteúdo para identificar se, na construção dos documentos, faz uso da valorização turística como atividade indutora do desenvolvimento local.

Trata-se de um estudo exploratório por proporcionar maior familiaridade com o problema, tornando-o mais explícito e descritivo, pois objetiva descrever as características de determinada população ou fenômeno (GIL, 2002). Os procedimentos metodológicos se concentraram no estudo e sistematização dos processos conceituais e documentais pertinentes ao objeto, com pesquisas bibliográfica e documental.

Os RIMAs selecionados para a análise foram obtidos no órgão ambiental estadual competente, a Superintendência Estadual do Meio Ambiente (SEMACE), em sua biblioteca virtual. A seleção dos empreendimentos baseou-se nos seguintes critérios: a) localização na zona costeira de municípios considerados ecoturísticos do Ceará; b) fossem de grande porte; e c) fossem destinados para o turismo e/ou lazer. Com esses critérios de pesquisa, chegou-se a amostra de 04 (quatro) RIMAs. Entendendo que outros documentos possam existir que não estejam disponíveis em meio digital, não sabendo, portanto, o universo total do objeto de estudo, procura-se analisar o objeto com uma abordagem qualitativa, evitando fazer generalizações, e buscando compreender de modo mais aprofundado cada um dos documentos. Posteriormente, houve a aplicação de técnicas investigativas para análise dos documentos, como a análise de conteúdo.

\section{Uso e ocupação do espaço litorâneo pelo turismo e a gestão dos impactos ambientais}

A soma de vários fatores contribuiu para o agravamento dos problemas e conflitos ambientais e sociais nas zonas litorâneas, ao longo do tempo. A ocupação histórica territorial do Brasil, que iniciou no sentido leste-oeste, a partir da zona costeira, com a instalação e desenvolvimento de cidades, como Rio de Janeiro, Salvador e Recife. Como apontam os autores a seguir:

\footnotetext{
O fenômeno da ocupação das faixas marítimas e das proximidades de rios e outros corpos d'água acompanhou a história humana, para satisfazer as suas necessidades. Porém, os ecossistemas frágeis e de vital importância para a cadeia alimentar marítima tornaram muitas ações, na costa do Brasil, altamente prejudiciais ao meio ambiente e as próprias comunidades locais (MELE et al., 2012, p. 157).
}

Em um momento mais recente, o uso das praias como espaço de lazer e convívio social, tornou-as foco para o investimento em turismo, em especial, para a construção de grandes empreendimentos, a exemplo dos resorts e empreendimentos turístico-imobiliários. Associa-se a esse fator, o fluxo maior de turistas como consequência da melhoria do nível socioeconômico dos 
brasileiros. Diante desta realidade, faz-se necessário criar mecanismos de proteção e conservação socioambiental, uma vez que "a importância deste espaço geográfico, [denominado zona costeira], que inclui faixa marítima e terrestre, decorre de suas peculiaridades ambientais e de sua importância econômica" (FREITAS; FREITAS, 2012, p. 257).

$O$ fato é que, desde a segunda metade do século $X X I$, a humanidade convive com sérios problemas ambientais, ocasionados especialmente pela ação antrópica, revelando um desequilíbrio na relação entre homem e natureza. Como aborda Vieira (2012), a questão ambiental emergente e urgente possibilitou a criação de instrumentos jurídicos, políticos e econômicos com a finalidade de conferir um nível mais elevado de proteção para o meio ambiente.

Em âmbito nacional, o dispositivo jurídico de maior referência é a Política Nacional do Meio Ambiente (PNMA), criada pela Lei 6.938/1981, que prevê em seus objetivos, a "compatibilização do desenvolvimento econômico-social com a preservação da qualidade do meio ambiente e do equilíbrio ecológico" (BRASIL, 1981). Os instrumentos associados à PNMA são: estabelecimento de padrões de qualidade, zoneamento ambiental, avaliação de impactos ambientais, licenciamento ambiental, criação de UCs e informações ambientais.

O foco do estudo está no licenciamento ambiental e seu essencial valor para incluir a sustentabilidade como base para o desenvolvimento local, além de refletir sobre a interdisciplinaridade dos instrumentos de gestão ambiental utilizados no processo licitatório. O objetivo é fomentar a reflexão crítica e interdisciplinar quanto ao licenciamento de empreendimentos turísticos e contribuir para aperfeiçoar as variáveis ambiental, social e econômica da sustentabilidade associadas a estes instrumentos, apresentando, em futuros estudos, a realidade das comunidades locais, em destinos ecoturísticos e os conflitos e dinâmicas surgidos a partir dele.

É o licenciamento ambiental que assegura e viabiliza operacionalmente a avaliação dos impactos e que define, após consulta à comunidade, as medidas mitigadoras e compensatórias necessárias para eliminar, reduzir e atenuar os danos ambientais das atividades efetiva e potencialmente poluidoras e degradadoras dos recursos naturais.

A Resolução CONAMA no 237/1997 regulamenta os aspectos do licenciamento ambiental e prevê uma série de etapas, dentre elas a elaboração de EIA e seus relatórios.

Válido registrar que a exigência de Estudo de Impacto Ambiental e respectivo Relatório (EIA/RIMA) para empreendimentos que alterem as características naturais da zona costeira relaciona-se com o caráter sensível que possui o meio ambiente costeiro e, portanto, devem possuir impactos adversos significativos no meio ambiente costeiro. O EIA possui uma metodologia criteriosa, com diretrizes gerais e conteúdo técnico especificados em norma, nos termos dos artigos 40 e 50 da Resolução/CONAMA n. 01/86, respectivamente. Por isso, além de o referido estudo ter 0 condão de contemplar todas as alternativas tecnológicas e de 
localização do projeto, identificar e avaliar sistematicamente os impactos, definir limites da área geográfica a ser afetada, deve considerar os planos e programas governamentais, propostos e em implantação na área de influência do projeto (VIEIRA, 2012, p. 86).

A última resolução citada representou um marco para a definição de critérios para a elaboração das avaliações de impacto ambiental. Em seu inciso III do art. $6^{\circ}$ determina que o EIA deve fazer a "definição das medidas mitigadoras dos impactos negativos, entre elas os equipamentos de controle e os sistemas de tratamento de despejos, avaliando a eficiência de cada uma delas" (BRASIL, 1986).

Os grandes empreendimentos representam uma mudança profunda na dinâmica social das comunidades onde se inserem, gerando conflitos de diversas ordens, ambientais, políticos, econômicos etc. Por sua vez, a maioria dos indicadores de sustentabilidade atualmente em uso são indicadores de pressão ambiental ou de qualidade ambiental, de aplicação mais restrita. Isso contrasta com o fato de os conflitos socioambientais se fundamentarem, em geral, nas respostas da sociedade às pressões sobre ela exercidas. Como exemplo, deve-se considerar as mobilizações de determinados grupos sociais, antes mesmo de o empreendimento iniciar o respectivo processo de licenciamento.

Por isso, a necessidade premente da avaliação de impactos. Como reitera Silva (1989 apud OLIVEIRA; MOURA, 2009), EIA é um processo de estudo realizado com 0 intuito de prever as consequências ambientais inerentes ao desenvolvimento de um projeto, que pode ser: a construção de uma hidrelétrica, irrigação em larga escala, um porto, uma fábrica de cimento ou um polo turístico.

Seu documento associado, o RIMA, apresenta os resultados dos estudos técnicos e científicos de avaliação de impacto ambiental. Segundo a Resolução CONAMA 001/86, deve ser apresentado de forma objetiva e adequada à sua compreensão, devendo as informações serem traduzidas em linguagem acessível para facilitar o entendimento sobre as vantagens e desvantagens do projeto e todas as consequências ambientais da sua implementação. Para tanto, deve conter, entre outros pontos, a descrição dos efeitos esperados das medidas mitigadoras em relação aos impactos negativos.

Seu propósito é de obter informações através do exame sistemático das atividades do projeto. Isto permite que se possa maximizar os benefícios, considerando os fatores saúde, bem-estar humano e meio ambiente como elementos dinâmicos no estudo para avaliação (PIMENTEL, 1992 apud OLIVEIRA; MOURA, 2009, p. 82).

Ressalta-se que os problemas, conflitos e agressões ao meio ambiente devem ser avaliados tendo como foco os danos à população, a empreendimentos vizinhos e ao meio físico e biológico. 
O turismo, por sua vez, é considerado uma atividade estratégica quando se trata dos efeitos multiplicadores na economia e como indutora do desenvolvimento. Diante desta condição, com frequência se apropria de espaços de grande beleza e diversidade ecológica e social, levando a questionamentos quanto à sua prática de forma coerente e equilibrada com os recursos naturais e culturais. Não sem propósito, surge, entre os teóricos da área, a perspectiva do turismo sustentável, com base em um novo modelo de desenvolvimento.

O turismo, no papel estratégico para o desenvolvimento em muitos países, por sua vez exerce um fascínio sobre os espaços e as pessoas e, sua presença muitas vezes se dá, em áreas frágeis sociocultural e ambiental. Com isso a implantação de empreendimentos imobiliários turísticos nestas áreas, trazem à discussão viabilidades e alternativas de convívio harmônico entre o direito ao desenvolvimento e a preservação dos recursos naturais, sociais e culturais de uma localidade, além de confrontar culturas (CIRILO, 2009, p. 5).

É preciso inibir o uso desenfreado de territórios com fragilidade ambiental, sem um planejamento adequado pautado em práticas conservacionistas, de modo que seja alcançado o equilíbrio entre desenvolvimento social e proteção ambiental. Uma das ações que merecem limitação, na zona costeira do nordeste brasileiro, é apontada por Cirilo (2009), a mercantilização turística das praias, devido às áreas naturais e sua diversidade, estabelecendo, com isso, a especulação imobiliária. As atividades econômicas ou de subsistência dão lugar a especulação intensa, que mesmo dando destaque aos municípios, promove alterações irreversíveis nas suas perspectivas de futuro.

Os efeitos das pressões do turismo sobre as faixas litorâneas e o crescimento do setor imobiliário turístico, comprovado pelo grande número de ofertas imobiliárias e de empreendimentos hoteleiros ao longo do litoral brasileiro, provocam críticas a essa forma de desenvolvimento do turismo, porque se prende à ocupação de extensas áreas, é feita de modo intensivo e gera repercussões negativas [...] (CIRILO, 2009, p. 4).

É incontestável que a presença destes projetos turísticos pode interferir de modo irreversível em alguns aspectos da comunidade que os recebe, inclusive na hospitalidade, "considerada um fenômeno que se amplia além do caráter socioantropológico, porque engloba a relação que se estabelece entre o espaço físico da cidade e seus habitantes [...]" (GRINOVER, 2001 apud CIRILO, 2009).

Os aspectos sociais devem estar inseridos no contexto da atividade turística, aplicando o conceito mais amplo de desenvolvimento, pois os impactos adversos às comunidades locais independem, em alguns casos, das medidas mitigadoras que visam o equilíbrio com o meio, apresentados nos 
EIAs. Tais empreendimentos podem vir a reforçar os contrastes sociais, tendo de um lado, o uso de espaço de grande beleza cênica, e de outro, a comunidade ali inserida que convive com este cenário, mas não consegue suprir suas necessidades por meio dele, promovendo os apartheids socioeconômicos ${ }^{2}$.

A sustentabilidade prega o equilíbrio, com a inserção das comunidades no processo decisório sobre a melhor alternativa para conduzir seu desenvolvimento. Como aponta Rabelo (2012, p. 14), este modelo não se limita a adequações ecológicas, deve priorizar "[...] a viabilidade econômica, social, cultural, espacial e a ecológica, tendo como elemento chave desse processo a participação dos atores sociais, implicando num formato de governança ambienta $\beta^{\prime \prime}$. Enquanto atores sociais envolvidos, os empreendedores têm importante papel a desempenhar:

[...] devem considerar os aspectos ambientais e sociais na direção de adotar posturas que levem em conta a sustentabilidade em suas várias dimensões e envolvem a necessidade de avaliar os impactos socioambientais considerando as alterações na natureza e no cotidiano das populações atingidas por esses empreendimentos (RABELO, 2012, p. 02).

Dentro da lógica de supervalorização dos espaços litorâneos, consolidase, no Brasil, nos últimos anos, uma nova modalidade de produção do espaço em que se apropria da praia enquanto mercadoria comercializada para uma parcela da população com poder aquisitivo superior aos habitantes nativos. Surgem novos atores sociais nessas localidades e a implantação de empreendimentos imobiliários, especialmente para veraneio e turismo.

A partir da problematização apresentada, que aborda o uso e ocupação dos espaços litorâneos pelo turismo e a adoção de licenciamento ambiental para inibir os impactos socioambientais adversos ocasionados por empreendedores, a pesquisa em tela propõe identificar essas questões em destinos ecoturísticos do litoral nordestino.

Destacam-se as comunidades litorâneas de destinos ecoturísticos, na direção de compreender a inter-relação estabelecida entre empreendimentos turísticos e a população local, uma vez que as inter-relações são fontes de conflitos quando interferem no modo de vida e dinâmica socioeconômica do local. Os questionamentos que surgem a partir da temática proposta são: os RIMAs de empreendimentos turísticos servem ao propósito da sustentabilidade em destinos ecoturísticos do litoral nordestino?; O EIA/RIMA é um instrumento interdisciplinar de adequação a uma convivência harmônica entre crescimento socioeconômico e meio ambiente? O turismo está sendo utilizado nos discursos como um fenômeno para fomentar a economia? 


\section{Ecoturismo e sustentabilidade em destinos litorâneos}

O turismo evidencia-se como uma das atividades que mais prosperam globalmente, tida como indutora do desenvolvimento local. Uma vasta abordagem conceitual é apresentada pelos teóricos da área, que concordam com os seguintes pontos: o turismo trata do deslocamento de pessoas para locais fora de sua residência e caracteriza-se por ser um fenômeno multisetorial e multidisciplinar. A atividade apresenta convergências e interfaces com diversas áreas do conhecimento, em especial, as ciências ambientais, geográfica, sociológica e administrativa.

Dentre os seus segmentos, destaca-se o turismo litorâneo, que representa uma das mais importantes práticas marítimas modernas, responsável por induzir o planejamento e desenvolvimento econômico (ARAÚJO, 2013). É fato que as atividades de turismo contribuem desde o século XX para o reordenamento do litoral, com valorização dos espaços litorâneos e reconfiguração das comunidades aí presentes.

Ao se perceber, num cenário regional nos anos entre 1980 e 1990, que o Nordeste brasileiro era detentor de um potencial turístico, sendo necessária, portanto, a consolidação do turismo, várias ações governamentais foram realizadas no intuito de promover mudanças significativas na visão das pessoas sobre o fenômeno turístico, desde o habitante local até o turista estrangeiro (ARAÚJO, 2013, p. 57).

Com a valorização da atividade, a sociedade passou a perceber o turismo como um negócio rentável e com oportunidades variadas para investimento. No caso brasileiro, a zona costeira tornou-se alvo da especulação imobiliária associada ao turismo.

Cabe lembrar que a zona costeira possui atributos paisagísticos singulares e raros que, consequentemente, contribuem para o aumento do preço da terra. Não raras vezes, mercado (imobiliário) e Estado andam juntos, bem nos moldes da teoria da máquina do crescimento, promovendo lugares de interesse à elite dominante daquele lugar (ARAÚJO, 2011, p. 204).

Dantas (2007, p. 23) examina a questão sob o contexto do nordeste brasileiro, onde a lógica de ordenação do território concentra-se na zona paralela à costa e "[...] transforma as zonas de praia em mercadoria nobre, dado que implica na modificação radical da paisagem litorânea". O autor complementa:

Em conformidade com esta lógica de valorização, as cidades litorâneas nordestinas são transformadas em pontos de recepção e de distribuição do fluxo turístico, colocando os espaços litorâneos de todos os municípios do estado sob a dependência direta das capitais e sem a mediação de outros centros urbanos intermediários. Grosso modo, significa lógica de dominação paralela à zona de praia, prolongando-se sobre o litoral e baseada no aeroporto [...] (DANTAS, 2007, p. 23). 
Contrapondo-se a ordem de supervalorização econômica do turismo, surgiram entre os teóricos da área, estudos que apontavam os efeitos adversos que a atividade poderia acarretar nos destinos turísticos, especialmente ao se tratar da massificação turística, com concentração de altos fluxos de turistas em um mesmo local, em especial, nas áreas naturais mais frágeis. Esses impactos podem ser de ordem econômica, social, ambiental, cultural, política etc.

Para citar alguns mais recentes, Rodrigues (2001), Ruschmann (2001), Pires (2001), Coriolano (2002), Dias (2003) discorrem em seus trabalhos sobre os impactos ambientais. Os problemas envolvem o uso dos recursos naturais, como o excesso de uso da água e resíduos gerados, desflorestamentos e retirada de madeira para construção de empreendimentos, poluição, lixo e resíduos sólidos em excesso, degradações de ecossistemas, dentre outros. Lage e Milone (1991) e Beni (2006) citam o principal benefício econômico do turismo, que é a geração de emprego e renda, entretanto pode gerar grande dependência em relação a um único setor (o turismo) e os empregos ofertados podem não absorver a população local por exigir maior qualificação.

Krippendorf (2001), Copper et al. (2001) e Coriolano (2002) reforçam os problemas sociais que referem-se às mudanças de comportamento e relacionamento nas comunidades pelo contato com turistas e visitantes. Crescimento desordenado do local, aumento da prostituição, aumento da criminalidade e violência, realocação da população local, são problemas sociais característicos de destinações turísticas, apresentados na literatura que versa sobre o tema.

Surge, em meados dos anos de 1990, o ecoturismo, baseado no modelo de desenvolvimento sustentável, e que reflete as inquietações sobre os impactos ambientais associados ao turismo. Como conceitua o Ministério do Turismo (2015), ecoturismo é "o segmento da atividade turística que utiliza, de forma sustentável, o patrimônio natural e cultural, incentiva sua conservação e busca a formação de uma consciência ambientalista por meio da interpretação do ambiente, promovendo o bem-estar das populações".

Com o intuito de inibir os impactos negativos associados à instalação de empreendimentos turísticos em áreas com fragilidade ambiental, são adotadas as medidas mitigadoras/compensatórias, apresentadas nos EIAs/RIMAs dos empreendimentos ao solicitarem 0 processo de licenciamento ambiental.

As mitigadoras são as que eliminam ou reduzem os impactos causados. As compensatórias, por sua vez, compensam os impactos que não conseguem ser eliminados ou resolvidos no próprio estudo. Cabe ao poder público fiscalizar se estão sendo cumpridas. A comunidade participa a partir de seus representantes locais e tem voz ativa nas audiências públicas, momento em que se apresenta e debate sobre o projeto (PREFEITURA DE PORTO ALEGRE, 2014). 
Em questões relacionadas com o ambiente, a expressão "compensação" é utilizada, em geral, em dois sentidos. Em sentido amplo, significa uma forma de reparação que compreende a recuperação de um ambiente alterado por uma atividade ou empreendimento, sem prejuízo de outras medidas adotadas - de natureza pecuniária ou não. Contudo, quando nos referimos a "medidas compensatórias", passamos a conferir um sentido estrito à expressão. Nesse caso, estaríamos nos referindo a medidas de cunho não necessariamente pecuniário (FARIA, 2008, p.10).

Ainda segundo Faria (2008), as medidas compensatórias são voluntariamente tomadas pelos agentes impactantes ou exigidas pelo órgão ambiental competente e destinadas a compensar impactos ambientais negativos. Destinam-se a compensar impactos irreversíveis e inevitáveis e diferem-se das medidas mitigadoras, que visam prevenir impactos adversos ou a reduzir aqueles que não podem ser evitados.

A partir da identificação e classificação dos impactos ambientais potenciais decorrentes das atividades de implantação e operação de empreendimentos turísticos, com uso de metodologias apropriadas ${ }^{4}$, a equipe multidisciplinar que realiza o EIA, propõe ações que visem à redução ou eliminação dos impactos negativos (medidas mitigadoras/compensatórias). Pode ainda propor ações para maximizar os impactos positivos (medidas potencializadoras), com vistas a otimizar as condições de instalação do empreendimento.

Faz-se oportuno avaliar os interesses dos atores locais impactados pelos empreendimentos e, consequentemente, identificar os conflitos socioambientais existentes, que possam não ter sido sanados com as medidas mitigadoras/compensatórias. Cabe fazer reflexões sobre este ponto tendo em mente a teoria dos apartheids socioeconômicos apresentada por Cirilo (2009), surgidos a partir dos conflitos entre comunidade local e grandes empreendimentos.

Os grandes empreendimentos podem elevar a qualidade de vida regional, pois com eles virão melhorias da infraestrutura urbana e regional. Porem, também é inegável que possam trazer, nesse panorama, apartheids socioeconômicos, uma vez que a internalização dos recursos gerados por esses empreendimentos não estarão ao alcance de todos. Alem disso, a hospitalidade dos lugares e das pessoas pode ser influenciada pela des(construção) das relações sociais, ambientais, culturais e até mesmo religiosas existentes no lugar e de algum modo nas pessoas que neles vivem ou visitam (CIRILO, 2009, p. 10) (grifo nosso).

Cabe, portanto, investigar se a prática do ecoturismo, no litoral nordestino, segue os princípios da sustentabilidade e qual o retorno que a atividade oferece para as comunidades locais. Um dos fatores que pode contribuir para isso é a análise crítica dos EIA/RIMAs de empreendimentos 
turísticos, já que justificam sua construção pelos impactos benéficos que promoverão no destino, em sua maioria, ecoturísticos, em especial em âmbito socioeconômico.

\section{Interdisciplinaridade e o processo de licenciamento ambiental}

A complexidade da problemática ambiental requer uma reflexão interdisciplinar, como aponta Coimbra (2000), recentemente aumenta-se a preocupação com a totalidade do planeta, estando inserida aí a sobrevivência do homem, e a consciência ecológica das inter-relações globais, em busca de uma solidariedade ecossistêmica.

Leff (1998 apud FLORIANI, 2000, p. 98) aborda o tema sob a perspectiva das ciências "a crítica epistemológica que ocorre no interior do saber ambiental não se compraz apenas com o saber teórico; reivindica igualmente uma práxis no âmbito da pesquisa que deve ser capaz de perceber, desvendar e elaborar um outro tipo de racionalidade ambiental', que converge para a interdisciplinaridade.

Para Coimbra (2000, p. 53), a interdisciplinaridade não se restringe "[...] a simples metodologia de ensino e aprendizagem, é também uma das molas propulsoras na reformulação do saber, do ser e do fazer [...]". O autor explica que,

Por virtude da etimologia ${ }^{5}$, a palavra traduz esse vínculo não apenas entre saberes, mas, principalmente, de um saber com outro saber, ou dos saberes entre si, numa sorte de complementaridade, de cumplicidade solidária, em função da realidade estudada e conhecida (COIMBRA, 2000, p. 56 grifo do autor).

Alvarenga et al (2011, p. 64) colocam que não se pode perder a visão disciplinar dentro do contexto interdisciplinar, pois "sabendo que as práticas interdisciplinares requerem sólidas formações disciplinares, [...] o pensamento interdisciplinar somente se constrói na relação com o disciplinar". Os autores avançam na discussão ao colocar a necessidade de uma visão crítica sobre o conhecimento gerado no campo de conhecimento disciplinar, o que permitirá abrir e transpassar fronteiras, propiciando encontros fertilizadores. $O$ turismo possibilita encontros fertilizadores quando estudado como um fenômeno essencialmente interdisciplinar, fazendo uso de outras disciplinas para contextualizar a atividade, especialmente da sociologia, geografia, antropologia e administração.

Os estudiosos concordam que existem variações da disciplinaridade. $O$ multidisciplinar evoca um aspecto quantitativo, sem necessariamente existir um nexo entre as abordagens, ou seja, o mesmo objeto pode ser estudado por várias disciplinas sem que haja um diálogo entre elas, enxergando o objeto com olhar unidisciplinar. O intradisciplinar é trabalhado no âmbito interno de uma disciplina, como um aprofundamento de um aspecto desta ciência. $\mathrm{O}$ interdisciplinar consiste num objeto em que duas ou mais disciplinas de modo intencional estabelecem nexos e vínculos para alcançar um conhecimento mais abrangente, diversificado e unificado. Existe ainda o transdisciplinar que 
é o passo além do interdisciplinar, promovendo um salto de qualidade, um grau elevado de conhecimentos e saber diferenciado. Seria uma assimilação progressiva de outros saberes que consiga ampliar o conhecimento e análise de uma problemática, a exemplo da questão ambiental, possibilitando uma síntese holística (COIMBRA, 2000).

O processo de licenciamento ambiental de grandes empreendimentos, inclusive os turístico-imobiliários, necessitam de uma intervenção interdisciplinar na formulação de seus documentos-chave, que respaldam a avaliação de impactos ambientais, o EIA e seu respectivo RIMA.

Entende-se por grandes empreendimentos turísticos aqueles projetos com finalidade turística, recreacional ou de lazer, sejam públicos ou privados, que mobilizam considerável volume de recursos e mão de obra, instalados em áreas com atributos ecológicos relevantes e que produzem alterações nos ecossistemas e no cotidiano das populações do território onde são instalados. Engloba, portanto, meios de hospedagem, complexos turísticos, empreendimentos imobiliários para segunda residência, parques temáticos, dentre outros.

Uma reflexão interdisciplinar sobre a construção do EIA/RIMA, desses empreendimentos, é necessária, pois o uso da interdisciplinaridade é uma exigência quando se busca analisar os impactos ambientais sob o viés econômico, social e ambiental e suas inter-relações. Souza (2009) problematiza o processo de licenciamento ambiental, enfatizando as fragilidades na obtenção da licença ambiental, que envolve basicamente: falta de quadro técnico no órgão ambiental o que acarreta equipes pequenas sem multidisciplinaridade 6 ; carência de um corpo técnico com qualificação adequada, comprometendo os Termos de Referência (TRs); a falta de estrutura do IBAMA e a legislação contribuem para que o empreendedor tenha controle financeiro, técnico e político sob o processo de licenciamento.

A interdisciplinaridade requer dos interessados, que pretendem utilizála, certas atitudes mentais, sociais e morais, além de uma atitude receptiva, honestidade intelectual, autocrítica e dose de humildade e da partilha de esforços e resultados (COIMBRA, 2000). A interdisciplinaridade, no contexto da construção dos EIA/RIMAs, mais que uma metodologia pronta, é uma prática que deve ser exercitada dentro das equipes que elaboram tais estudos.

\section{Reflexões críticas acerca dos RIMAs de empreendimentos turístico- imobiliários de destinos ecoturísticos do Ceará}

A análise dos 04 RIMAs de empreendimentos turístico-imobiliários, enquanto instrumentos de gestão ambiental fundamentais para direcionar 0 uso e ocupação do solo em destinos ecoturísticos, mostra um cenário desfavorável no alcance da interdisciplinaridade. Um dos pontos críticos corrobora o que problematizou Souza (2009) sobre a obtenção da licença ambiental, que os documentos analisados foram elaborados por equipes técnicas pequenas e com formação profissional pouco diversificada. A maioria dos profissionais são geólogos (6), seguido por geógrafos (5) e biólogos (4). Constam ainda pedagogo (1), engenheiro de pesca (1), engenheiro civil (1), engenheiro florestal (1), e tecnólogo em saneamento ambiental (1). 
Como preconiza a interdisciplinaridade é importante o envolvimento de pesquisadores com formações diversas no estudo de um objeto de estudo, a fim de alcançar um conhecimento holístico a cerca do mesmo. A legislação ambiental vigente no país estabelece que o EIA contemple os impactos ambientais sob as perspectivas dos meios: físico (solo, água e ar), socioeconômico (uso e ocupação do solo, aspectos sociais e econômicos, e aspectos arqueológicos); e biótico (flora e fauna), identificando as possíveis mudanças na dinâmica do local.

Sob este parâmetro, percebe-se, nos RIMAs estudados, a carência de profissionais ligados aos âmbitos social e econômico, tais como sociólogos, antropólogos, arqueólogos e economistas. Carecem, ainda, de profissionais da área de turismo e lazer, uma vez, que a finalidade dos empreendimentos é turístico-recreativo. Em relação ao RIMA do empreendimento da Praia de Guajiru, fala-se especificamente que as obras podem ocasionar riscos ao patrimônio arqueológico do local, mas não foi inserido um profissional especialista na área na equipe técnica.

Os RIMAs avaliados podem ser caracterizados enquanto estudos multidisciplinares, pois cada especialista analisa o objeto de estudo sob o enfoque de sua disciplina, exercendo a unidisciplinaridade.

Observou-se, de modo positivo, que os documentos afirmam o respeito ao meio ambiente e aos princípios da sustentabilidade, por outro lado não apresentam conceitos e definições para respaldar essa preocupação. O uso de terminologias e definições apropriadas é essencial para validar estudos científicos. No documento associado ao município de Cascavel, por exemplo, a descrição dos equipamentos a serem instalados, prevê a construção de 03 trilhas de acesso ao Rio Malcozinhado e 02 ancoradouros para pequenas embarcações "que objetivam o desenvolvimento de atividades de ecoturismo, - que necessitará da intervenção na $A P P^{7}$ do rio Malcozinhado" (GEOCONSULT, 2011). É preciso uma reflexão interdisciplinar quanto a estas obras e conceitos expostos. Analisa-se a definição de ecoturismo, que trata da prática do turismo segundo os princípios da sustentabilidade. Entretanto, não deixa claro se as atividades ecoturísticas a serem implantadas condizem com o que prega o segmento do turismo sustentável, pois deverão impactar uma área de proteção permanente, as trilhas não são descritas como interpretativas, os ancoradouros poderão promover impactos ao meio e não são apresentadas as formas de inserção da comunidade local.

A metodologia empregada para avaliação dos impactos ambientais, em todos os RIMAs, foi o "Check List". Os impactos ambientais na área de influência funcional do projeto de implantação e operação, registrados no RIMA de cada empreendimento, bem como as justificativas para sua implantação, são apresentados na Tabela 1, a seguir: 
Tabela 1: impactos ambientais dos empreendimentos.

Table 1: Environmental impacts of the projects.

\begin{tabular}{|c|c|c|c|c|}
\hline Local/ano & $\begin{array}{c}\text { Número } \\
\text { total }\end{array}$ & $\begin{array}{c}\text { Impacto } \\
\text { de } \\
\text { caráter } \\
\text { benéfico }\end{array}$ & $\begin{array}{l}\text { Impacto } \\
\text { de caráter } \\
\text { adverso }\end{array}$ & Análise dos impactos \\
\hline $\begin{array}{c}\text { Paracuru } \\
\text { - CE - } \\
2011\end{array}$ & $\begin{array}{c}241 \\
(100 \%)\end{array}$ & $\begin{array}{c}113 \\
(46,89 \%)\end{array}$ & $\begin{array}{c}128 \\
(53,11 \%)\end{array}$ & $\begin{array}{l}\text { "[...]os efeitos adversos do empreendimento } \\
\text { recairão principalmente sobre os componentes } \\
\text { físicos e biológicos da área de influência direta, } \\
\text { [...] ocorrerão alterações irreversíveis no } \\
\text { comportamento morfológico, topográfico e na } \\
\text { dinâmica sedimentar, além de perda de } \\
\text { biodiversidade local e afugentamento da fauna, } \\
\text { entre outros. No entanto, os efeitos benéficos } \\
\text { gerados compensarão as adversidades, [...] } \\
\text { desencadeando o crescimento dos setores } \\
\text { produtivos e gerando divisas para o município } \\
\text { de Paracuru e para o Estado do Ceará. Os } \\
\text { efeitos positivos são identificados principalmente } \\
\text { no meio socioeconômico, destacando-se maior } \\
\text { oferta de empregos, com oportunidades de } \\
\text { trabalho para a população economicamente } \\
\text { ativa" }\end{array}$ \\
\hline $\begin{array}{c}\text { Caponga } \\
\text { (Cascavel } \\
- \text { CE) } \\
2011\end{array}$ & $\begin{array}{c}269 \\
(100 \%)\end{array}$ & $\begin{array}{c}137 \\
(50,93 \%)\end{array}$ & $\begin{array}{c}132 \\
(49,07 \%)\end{array}$ & $\begin{array}{l}\text { "Os impactos adversos de grande magnitude [...] } \\
\text { relacionados a limpeza do terreno, com a perda } \\
\text { do potencial florístico; a modificação da } \\
\text { paisagem; a alteração morfológica do terreno e } \\
\text { da dinâmica local; aumento da demanda de } \\
\text { água e a produção de resíduos sólidos. Os } \\
\text { impactos benéficos de grande magnitude [...] } \\
\text { oferta de empregos permanentes, } \\
\text { desenvolvimento do turismo e oferta de } \\
\text { infraestrutura" "Com o empreendimento a área } \\
\text { de influência direta sofrerá alterações em alguns } \\
\text { parâmetros físicos e biológicos, entretanto, os } \\
\text { efeitos benéficos gerados compensarão as } \\
\text { adversidades, posto que os benefícios } \\
\text { refletirão sobre a área de influência indireta, } \\
\text { desencadeando o crescimento dos setores } \\
\text { produtivos e gerando divisas para o município } \\
\text { de Cascavel e para o Estado do Ceará" }\end{array}$ \\
\hline $\begin{array}{l}\text { Flecheiras } \\
\text { (Trairi - } \\
\text { CE) } \\
2013\end{array}$ & $\begin{array}{c}117 \\
(100 \%)\end{array}$ & $\begin{array}{c}67 \\
(57,26 \%)\end{array}$ & $\begin{array}{c}50 \\
(42,74 \%)\end{array}$ & $\begin{array}{l}\text { "a Área de Influência Direta sofrerá alterações } \\
\text { em vários parâmetros físicos e biológicos, mas } \\
\text { em grande parte de pequena magnitude e de } \\
\text { curta duração. Entretanto, os efeitos benéficos } \\
\text { compensarão, pois refletirão no crescimento } \\
\text { dos setores produtivos locais, no } \\
\text { crescimento do estado e do município de } \\
\text { Trairi" }\end{array}$ \\
\hline $\begin{array}{l}\text { Praia de } \\
\text { Guajiru } \\
\text { (Trairi - } \\
\text { CE) s.d. }\end{array}$ & $\begin{array}{c}115 \\
(100 \%)\end{array}$ & $\begin{array}{c}67 \\
(58,26 \%)\end{array}$ & $\begin{array}{c}48 \\
(41,74 \%)\end{array}$ & $\begin{array}{l}\text { "Os efeitos adversos do projeto recairão } \\
\text { principalmente sobre os componentes físicos da } \\
\text { área de influência direta, uma vez que ocorrerão } \\
\text { alterações irreversíveis no } \\
\text { comportamento morfológico, topográfico e na } \\
\text { dinâmica sedimentar, entre outros". "as obras } \\
\text { do empreendimento envolvem unicamente } \\
\text { riscos com relação ao patrimônio } \\
\text { arqueológico". "[...] entretanto, os efeitos } \\
\text { benéficos gerados compensarão as } \\
\text { adversidades, posto que os benefícios reflitam } \\
\text { sobre a área de influência indireta, } \\
\text { desencadeando o crescimento dos setores } \\
\text { produtivos e gerando divisas para o Município } \\
\text { de Trairi e para o Estado do Ceará" }\end{array}$ \\
\hline
\end{tabular}

Fonte: autora (adaptado dos RIMAs estudados).

Source: author (adapted from RIMA studied). 
Percebe-se nas falas apresentadas que os documentos reforçam o caráter econômico associado à atividade turística, como o crescimento dos setores produtivos, geração de divisas, oferta de empregos permanentes e oferta de infraestrutura, com intuito de obter a aprovação do projeto, apresentando os aspectos negativos, demonstrando, entretanto, a compensação dos mesmos pelos aspectos positivos. E o fazem, utilizando o mesmo discurso, muitas vezes com as mesmas palavras.

Segundo os autores que estudam os impactos econômicos do turismo (LAGE; MILONE, 1991 e BENI, 2006), a oferta de empregos, em decorrência das obras turísticas, é temporária e os postos de trabalho permanentes criados não absorvem a comunidade local, pois necessitam de uma qualificação que não possuem. Uma das soluções para isso, por exemplo, seria inserir nos EIA/RIMAs medidas compensatórias que ampliassem a qualificação da população do entorno do empreendimento, com oferta de cursos de capacitação profissional. Neste sentido, estariam em consonância com os preceitos do ecoturismo, uma vez que seria explícito o retorno às comunidades locais e o desenvolvimento sustentável.

Outros elementos não discutidos, por falta do exercício da interdisciplinaridade para construção destes documentos, são os impactos socioculturais associados à instalação e operação dos empreendimentos turísticos, como mudanças de comportamento e relacionamento nas comunidades pelo contato com turistas e visitantes, crescimento desordenado do local, aumento da prostituição, aumento da criminalidade e violência, realocação da população local (KRIPPENDORF, 2001; COPPER et al., 2001 e CORIOLANO, 2002). Caberia a proposição de medidas compensatórias destinadas a atenuar essas questões.

Em relação ao segundo ponto, que trata da análise do conteúdo em prol do fomento da atividade turística, é comum a argumentação de que o turismo é indutor do desenvolvimento local. No RIMA do empreendimento de Caponga (2011), justifica-se a implantação do empreendimento, pois a área possui potencial para exploração turística, "[...] ressaltando-se que sua localização geográfica é estrategicamente favorável ao desenvolvimento do turismo receptivo, uma vez que está situada numa região de paisagem singular, de clima agradável e de alto padrão de qualidade ambiental" (GEOCONSULT, 2011). No RIMA do empreendimento de Paracuru, elaborado pela mesma consultoria, tem-se o mesmo texto: " $A$ justificativa do empreendimento parte do pressuposto de que a área apresenta potencialidade à exploração turística, [...]"(GEOCONSULT, 2011), ressalta-se a localização geográfica e estratégica para desenvolver o turismo receptivo, pois possui paisagem singular, clima agradável e alto padrão de qualidade ambiental. Mesmo em documentos elaborados por outra consultoria, verifica-se a ocorrência de repetições, caso do RIMA do empreendimento de Guajiru ${ }^{8}$.

No empreendimento de Flecheiras (2013), a justificativa locacional apresenta dentre outras questões: os aspectos paisagísticos e ecológicos do ambiente do entorno, a boa localização geográfica com relação a faixa litorânea do município de Trairi, as vantagens econômicas, e as perspectivas de desenvolvimento da região, com o crescimento turístico. Reforçando, portanto, a mercantilização das praias a partir do turismo. 
O turismo, nos 04 RIMAs investigados a partir da análise do conteúdo, é enaltecido como uma atividade capaz de alavancar o desenvolvimento local, explorando os recursos naturais de singular beleza cênica, presentes na faixa litorânea do Ceará. Entretanto, a gestão sustentável de qualquer destinação turística, tenha vocação ecoturística ou não, deve estar pautada em um planejamento mais abrangente, englobando diferentes políticas públicas nas áreas de saúde, segurança pública, educação, urbanização, turismo, dentre outras.

\section{Considerações Finais}

Nos 04 RIMAs avaliados, os benefícios gerados com a implantação dos empreendimentos turístico-imobiliários reforçam os aspectos socioeconômicos, como o crescimento dos setores produtivos, geração de divisas e renda, oferta de empregos permanentes e oferta de infraestrutura a partir do turismo para justificar a aprovação dos projetos. Os meios biótico e físico acabam sendo não priorizados em prol do meio socioeconômico.

Isso indica uma supervalorização da atividade turística em prol de outros setores. O turismo vem sendo utilizado em discursos desenvolvimentistas como atividade capaz de alavancar o crescimento econômico de localidades, no caso deste estudo, de destinos ecoturísticos, direcionando os investimentos para implantação de empreendimentos turístico-imobiliários na zona costeira do Ceará e gerando consequências adversas como a mercantilização das praias e a especulação imobiliária.

Quanto à prática da interdisciplinaridade para a construção do instrumento de gestão, o RIMA, observou-se que as equipes técnicas são reduzidas e não tem especialização para atestar determinadas questões que requerem um olhar interdisciplinar. São caracterizadas, portanto, como multidisciplinares e não interdisciplinares, o que compromete os estudos de impacto ambiental.

Por fim, é preciso repensar as metodologias de análise de impactos ambientais que sejam integradas às diversas ciências e possam ser investigadas com um olhar interdisciplinar. Para isso, na elaboração dos EIA/RIMAs, deve-se buscar um coordenador para as equipes técnicas que trabalhe no contexto interdisciplinar para alcançar resultados que abranja a totalidade complexa do local e que formate um novo modelo de equipe, no qual os profissionais dialoguem entre si, para alcançar um objetivo comum: a sustentabilidade.

\section{Referências bibliográficas}

AMBIENTAL CONSULTORIA E PROJETOS. Condomínio Residencial Flecheiras Jardins. Relatório de Impacto Ambiental. Fortaleza, 2013.

AMBIENTAL CONSULTORIA E PROJETOS. Village Viva Pecém. Relatório de Impacto Ambiental. Fortaleza, 2013. 
ARAÚJO, C.P. Terra à vista! O litoral brasileiro na mira dos empreendimentos turísticos imobiliários. 2011. 368 f. Tese - Faculdade de Arquitetura e Urbanismo - USP, São Paulo, 2011.

ARAÚJJO, E.F. As políticas públicas e os espaços turísticos no litoral da Região Metropolitana de Fortaleza. In: QUEIROZ, A. et al. Maritimidade na metrópole: estudos sobre Fortaleza-CE. Porto Alegre: Liro, 2013.

A ROTA. Rota das Emoções. Jeri - Delta - Lençóis. Disponível em: $<$ http://www.rotadasemocoes.com.br/index.html>. Acesso em: 29 set. 2014.

BENI, M.C. Política e planejamento de turismo no Brasil. São Paulo: Aleph, 2006.

BRASIL. Lei 6938, de 31 de agosto de 1981. Dispõe sobre a Política Nacional do Meio Ambiente... Disponível em: $<$ http://www.planalto.gov.br/ccivil 03/leis/l6938.htm> Acesso em: 01 ago 2014.

BRASIL. Resolução CONAMA 001 de 23 de janeiro de 1986. Disponível em: $<$ http://www.mma.gov.br/port/conama/res/res86/res0186.html> Acesso em: 13 ago 2014.

CIRILO, L. O imobiliário turístico e as questões socioambientais como influência na hospitalidade. Estudo de caso o nordeste brasileiro. Gestion Turística, Valdivia, edição especial, 77-94, mar. 2009 (Universidad Austral de Chile).

COOPER, C. et al. Turismo: princípios e práticas. 2. ed. Porto Alegre: Bookman, 2001.

CORIOLANO, L.N.M.T. O ecoturismo e os hospedes da natureza. In: BARRETO, M.; TAMANINI, E. Redescobrindo a ecologia do turismo. Caxias do Sul: Educs, 2002.

DANTAS, E.W.C. Imaginário social nordestino e políticas de desenvolvimento do turismo no nordeste brasileiro. Espaço e tempo (GEOUSP), São Paulo, n. 22, p 09-30, 2007.

DIAS, R. Turismo sustentável e meio ambiente. Reinaldo Dias. São Paulo: Atlas, 2003.

FARIA, I.D. Compensação ambiental: os fundamentos e as normas; a gestão e os conflitos. Brasília: Consultoria Legislativa do Senado Federal, 2008. (Série Textos para Discussão).

FREITAS, V.P.; FREITAS, D.A.P. A proteção do meio ambiente na zona costeira. In: GRANZIERA, M.L.M.; GONÇALVES, A. (Organizadores). Os problemas da zona costeira no Brasil e no mundo. Santos: Editora Universitária Leopoldianum, 2012.

GEOCONSULT - CONSULTORIA, GEOLOGIA E MEIO AMBIENTE LTDA. Águas Belas Golf Resort e SPA. Relatório de Impacto Ambiental. Fortaleza, 2011.

GEOCONSULT - CONSULTORIA, GEOLOGIA E MEIO AMBIENTE LTDA. Complexo turístico Dunas do Paracuru. Relatório de Impacto Ambiental. Fortaleza, 2011. 
GEOSIS. Sol e Mar Beach Resort. Relatório de Impacto Ambiental. Fortaleza, s.d.

GRANZIERA, M.L.M.; GONÇALVES, A. (orgs). Os problemas da zona costeira no Brasil e no mundo. Santos: Editora Universitária Leopoldianum, 2012.

KRIPPENDORF, J. Sociologia do turismo: para uma nova compreensão do lazer e das viagens. São Paulo: Aleph, 2001.

LAGE, B.H.G.; MILONE, P.C. Economia do turismo. Campinas, SP: Papirus, 1991.

LEMOS, A.I.G. Turismo: impactos socioambientais. 3. ed. São Paulo: Hucitec, 2001.

MELE, J.L.; MELE, P.W.; MELE, J.T.W. Infrações ambientais administrativas na zona costeira. In: GRANZIERA, M.L.M.; GONÇALVES, A. (orgs). Os problemas da zona costeira no Brasil e no mundo. Santos: Editora Universitária Leopoldianum, 2012.

MINISTÉRIO DO TURISMO. Ecoturismo. Marcos conceituais. Brasília, 2015. Disponível em: $<$ http://www.turismo.gov.br/turismo/programas acoes/regionalizacao turism o/estruturacao segmentos/ecoturismo.html>. Acesso em: 08 abr. 2015

OLIVEIRA, E.S. Impactos socioambientais e econômicos do turismo e suas repercussões no desenvolvimento local: o caso de Itacaré - Bahia. 2008. 153 f. Dissertação (Mestrado em Cultura e Turismo) - Universidade Estadual de Santa Cruz/Universidade Federal da Bahia, Ilhéus, 2008.

OLIVEIRA, F.C.; MOURA, H.J.T. Uso das metodologias de avaliação de impacto ambiental em estudos realizados no Ceará. Pretexto, Belo Horizonte, v. 10, n. 4, p. 79-98, out./dez. 2009.

PREFEITURA DE PORTO ALEGRE. SMURB. O que são projetos especiais? Disponível em: $<$ http://www2.portoalegre.rs.gov.br/spm/default.php?p secao=194>. Acesso em: 23 ago 2014

RABELO, J.B. Governança e impactos ambientais na instalação de empreendimentos urbanos. Encontro de Ciências Sociais do Norte e Nordeste, Pré-Alas Brasil, XV, 2012, Teresina. Anais... Teresina, 2012.

RODRIGUES, A.B.. Turismo e espaço: rumo a um conhecimento transdisciplinar. 3. ed. São Paulo: Hucitec, 2001.

RUSCHMANN, D.V.M. Turismo e planejamento sustentável: a proteção do meio ambiente. 8. ed. Campinas: Papirus, 2001.

VIEIRA, G.L.G. Avaliação ambiental e empreendimentos costeiros. In: GRANZIERA, M.L.M.; GONÇALVES, A. (orgs). Os problemas da zona costeira no Brasil e no mundo. Santos: Editora Universitária Leopoldianum, 2012. 


\section{Notas:}

1 São frutos da associação entre segundas residências e resorts (ARAÚJO, 2011). Vale ressaltar que o imobiliário turístico no nordeste é composto com significativa representatividade pelos resorts, consequência de investimentos estrangeiros que preveem a construção de grandes empreendimentos e condomínios residenciais ao longo do litoral brasileiro.

${ }^{2}$ Conceito a ser trabalhado mais adiante.

${ }^{3}$ Segundo Rabelo (2012, p. 05), "se constitui em um conjunto de procedimentos que possibilitem a construção coletiva de soluções para os problemas ambientais com a participação dos atores sociais".

4 "Existem, basicamente, as distintas linhas metodológicas desenvolvidas para a avaliação de impactos ambientais: Metodologias espontâneas (Ad hoc), Listagens (Check-list), Matrizes de interações, Redes de interações (Networks), Metodologias quantitativas, Modelos de simulação, Mapas de superposição (Overlays), Projeção de cenários, entre outras" (OLIVEIRA; MOURA, 2009, p. 84).

${ }^{5}$ A preposição latina inter, se isolada, significa: 1 . Entre; no meio de; no número de; junto de. - 2. Durante; no espaço de; dentro de. - 3. Etim. Entre (fal. de duas coisas ou pessoas) (TORRINHA, 1945 apud COIMBRA, 2000, p. 54).

${ }^{6} \mathrm{O}$ autor dialoga em termos de multi e não interdisciplinaridade que deveria ser a base para a construção dos EIAs.

${ }^{7}$ APP - Área de Proteção Permanente.

8 "A justificativa do empreendimento parte do pressuposto de que a área apresenta potencialidade à exploração turística, ressaltando-se que sua localização geográfica é estrategicamente favorável ao desenvolvimento do turismo receptivo, uma vez que se encontra situada numa região de paisagem singular, de clima agradável e de alto padrão de qualidade ambiental" (GEOSIS, s.d.).

Thays Regina Rodrigues Pinho: Universidade Federal do Maranhão, São Luís, MA, Brasil.

E-mail: thayspinho@hotmail.com

Link para o currículo Lattes: http://lattes.cnpq.br/6971545107452648

Data de submissão: 28 de abril de 2015

Data de recebimento de correções: 29 de outubro de 2015

Data do aceite: 29 de outubro de 2015

Avaliado anonimamente 